\title{
POLA INTERAKSI SOSIAL PENGEMUDI TRANSPORTASI ONLINE GRAB DI KOTA SINGARAJA SEBAGAI SUMBER BELAJAR SOSIOLOGI DI SMA
}

\author{
Delfin Reza Fahlefi ${ }^{1}$, Dr. I Wayan Mudana, M.Si ${ }^{2}$, Dr. I Nyoman Sila, M.Hum ${ }^{3}$ \\ Jurusan Sejarah, Sosiologi, dan Perpustakaan \\ Universitas Pendidikan Ganesha \\ Singaraja, Indonesia
}

\begin{abstract}
e-mail: \{delfinfahlefi522@gmail.com¹,mudanawayan60@gmail.com². nyoman.sila99@gmail.com²\}@undiksha.ac.id
\end{abstract}

\begin{abstract}
ABSTRAK
Penelitian ini memiliki rumusan masalah (1) faktor apakah yang memengaruhi munculnya penggunaan fake gps dikalangan pengemudi Grab Singaraja? (2) bagaimana pola interaksi antara pengemudi Grab yang menggunakan aplikasi fake gps dengan yang tidak menggunakan aplikasi fake gps? (3) aspek-aspek apa sajakah dari interaksi sosial diantara pengemudi Grab Singaraja yang dapat dijadikan sumber belajar sosiologi kelas X di SMA?. Dengan tujuan untuk (1) mendeskripsikan faktor pengemudi Grab menggunakan aplikasi fake gps dan yang tidak menggunakan aplikasi fake gps, (2) mendeskripsikan pola interaksi antara pengemudi yang menggunakan aplikasi fake gps dan yang tidak menggunakan aplikasi fake gps, (3) mendeskripsikan bahwa kelompok dalam masyarakat bisa dijadikan sumber belajar sosiologi kelas $X$ di SMA. Dalam penelitian ini menggunakan pendekatan kualitatif deskriptif. Penentuan informan dalam penelitian ini yaitu menggunakan teknik purposive sampling (1) observasi, (2) wawancara in-dept interview, (3) studi dokumentasi. Teknik analisis data yang digunakan pada penelitian ini yaitu pengumpulan data, reduksi data, penyajian data, dan penarikan kesimpulan. Hasil penelitian menunjukan bahwa (1) faktor munculnya penggunaan aplikasi fake gps di Kota Singaraja adalah untuk mempermudah dalam mendapat pelanggan akan kebutuhan pencapaian syarat insentif Grab, (2) pola interaksi pengemudi Grab yang menggunakan fake gps dan yang tidak mengunakan fake gps terbagi menjadi dua bentuk yaitu interaksi yang asosiatif dan disosiatif, (3) terdapat aspek-aspek sosiologis yang dapat dijadikan sumber belajar sosiologi di SMA yakni bentuk pola interaksi pengemudi transportasi online Grab yang asosiatif dan disosiatif. Penelitian ini berimplikasi kepada pengemudi transportasi online, terbentuknya pola interaksi dan pendidik mata pelajaran sosiologi.
\end{abstract}

Kata kunci: Grab, fake gps, Pola Interaksi, penyimpangan, sumber belajar

\footnotetext{
ABSTRACT

This research has problem formulation (1) what factors influence the emergence of the use of fake gps among Singaraja Grabs? (2) what is the pattern of interaction between Grab drivers who use fake gps applications and those who do not use fake gps applications? (3) what aspects of social interaction between Singaraja Grab drivers can be used as source of learning sociology in class $X$ in high school?. With the aim to (1) to describe the factors of the Grab drivers who used fake gps application and the drivers who did not use fake gps application, (2) to describe the interaction patterns between the drivers who used fake gps application and did not
} 
use fake gps application, (3) to describe that, groups in society can be used as a source of learning material for sociology class in tenth grade in high school (SMA). In this study using a descriptive qualitative approach. Informant data collection techiques using purposive sampling. Determinan of informants in this study purposive sampling technique (1) observation, (2) in-dept interview, (3) documentation study. Data analysis techniques used in this study are data collection, data reduction, data presentation, and drawing conclusions the result showed that (1) the emergence factor of the use of fake gps application in the city Singaraja is to make it easier to get customers to the needs of achieving the Grab incentive recuirrements, (2) Grab driver interaction patterns that use fake gps are divided into two forms namely associative and dissociative interaction, (3) there are sociological aspect that can be used as a source of learning sociology in high school that is a form of interaction patterns of online transportation drivers associative and dissociative Grab. This research has implications for online transportation drivers, the formation and educator in sociology subjects.

Keywords : Grab, fake gps, interaction patterns, irregularities, source of learning

\section{PENDAHULUAN}

$\mathrm{Di}$ era modern ini, kita bisa merasakan kecanggihan teknologi, salah satu diantaranya adalah teknologi transportasi berbasis aplikasi atau sering disebut transportasi online. Transportasi adalah sarana yang umumnya dipergunakan untuk mengangkut manusia atau barang dari suatu tempat ke tempat yang lain. Transportasi online merupakan contoh keluaran dari pengembangan teknologi dengan berbasis aplikasi, awal kemunculan teknologi ini disambut dengan baik karena dianggap inovasi terbaik di era sekarang ini (Wahyusetyawati, 2017:7). Salah satu transportasi online yang ada di Indonesia adalah Grab. Grab adalah perusahaan yang berasal dari Singapura, perusahaan ini didirikan oleh Anthony Tan dan Tan Hooi Ling. Perusahaan ini memiliki layanan berbasis aplikasi yang menyediakan transportasi. Grab sudah tersebar di berbagai Kota yang ada di Indonesia.

Salah satu daerah yang sudah ada Transportasi online Grab adalah Kota Singaraja, Bali. Grab mulai masuk di Kota Singaraja sejak tahun 2017 akhir, pada saat itu manajemen Grab yang berasal dari Denpasar gencar melakukan promosi untuk mendapatkan mitra dan merchant.

Selanjutnya lambat laun mitra Grab di Kota Singaraja bertambah banyak.
Dengan bertambahnya mitra, manajemen Grab membentuk suatu komunitas khusus mitra agar mempermudah dalam koordinasi dan menyebarkan informasi kepada seluruh anggota. Seiring berjalannya waktu mitra Grab menjadi semakin banyak, persaingan pun menjadi semakin ketat. Berbagai cara dilakukan untuk mendapatkan orderan, seperti mencari daerah ramai order, pengemudi transportasi Grab terus keliling dari merchant satu ke merchant yang lain, pengemudi melakukan dengan cara bertahap hingga mendapat orderan yang diinginkan kemudian ada yang menggunakan aplikasi tambahan, salah satu aplikasi tambahan tersebut adalah Fake gps. Secara bahasa Fake artinya adalah palsu sedangkan GPS adalah singkatan dari Global Positioning System dalam Bahasa Indonesia berarti Sistem Pemosisi Global. Global Posisitioning System merupakan sistem yang berguna untuk menentukan letak di suatu daerah dengan bantuan dari penyelarasan satelit. Selanjutnya para developer pun menciptakan aplikasi pendukung layanan transportasi online seperti Fake gps. Aplikasi Fake gps merupakan salah satu aplikasi yang bisa memanipulasi posisi kita sesuai keinginan pengguna. Penggunaan Fake gps ini sering disalah gunakan oleh berbagai golongan. Salah 
satu golongan tersebut adalah pengemudi transportasi online Grab dipergunakan untuk memanipulasi wilayah yang bertujuan untuk mendapatkan orderan lebih banyak, karena titik GPS diletakkan pada daerah yang ramai order (Santoso, 2018).

Penggunaan Fake gps semakin populer bagi golongan pengemudi transportasi online, padahal sudah jelas bahwa pengguna aplikasi fake gps sudah melanggar dari aturan Grab, ini sesuai dengan kode etik umum Grab pada nomor 10 yang tertulis "Mencurangi atau memanipulasi sistem Grab milik sendiri atau orang lain untuk alasan apapun, termasuk untuk mendapatkan order/uang tambahan/bonus/insentif". penggunaan aplikasi Fake gps sekarang sudah mulai populer digunakan pada pengemudi transportasi online di Kota Singaraja, akan tetapi untuk Kota Singaraja ini masih menjadi tanda tanya, karena pada Kota ini sama seperti kota-kota lain ada pengemudi trasnportasi online yang menggunakan aplikasi Fake gps dan ada yang tidak menggunakan, hal ini masih menjadi perbincangan yang sangat menarik pada kalangan pengemudi transportasi online, karena menuai pro dan kontra. Maka dari itu perlu dilakukan penelitian lebih lanjut untuk mengetahui alasasan pengemudi Grab Singaraja menggunakan aplikasi fake gps. Dengan adanya interaksi antara pengemudi transportasi online tersebut, peneliti ingin mengkaji lebih lanjut untuk melihat apakah terdapat permasalahan dalam proses interaksi sosial yang terjadi di setiap harinya, dengan melihat proses interaksinya, bisa melihat pola interaksi yang terjadi antar pengemudi transportasi Grab di Kota Singaraja, Bali. Berdasarkan fenomena tersebut bisa dilihat dari segi prespektif sosiologis dan bisa digunakan untuk sumber belajar sosiologi di SMA yang bersifat konstektual.

Pola Interaksi Pengemudi transportasi online Grab ini dapat ditelaah dengan teori kebutuhan McClelland, konsep interaksi sosial, penyimpangan sosial, dan konsep sumber belajar. Dalam penelitian ini diformulasikan 3 (tiga) rumusan masalah yang terdiri dari (1) faktor apakah yang memengaruhi munculnya penggunaan fake gps dikalangan pengemudi Grab di Singaraja?, (2) bagaimana pola interaksi antara pengemudi Grab yang menggunakan aplikasi fake gps dan yang tidak menggunakan aplikasi fake gps?, (3) aspek-aspek apa sajakah dari interaksi sosial pengemudi Grab Singaraja yang dapat dijadikan sumber belajar sosiologi kelas X di SMA?.

Pendekatan penelitian dalam tulisan ini adalah penlitian kualitatif deskriptif. Pada dasarnya metode penelitian kualitatif digunakan sebagai penelitian untuk mengamati suatu kasus. Dengan demikian proses pengumpulan serta analisis data bersifat studi kasus. Karena terdapat kekhususan metodemetode kualitatif ini sering digunakan oleh pra pakar praktisi seperti konsultan, manajer, penyuluh lapangan dan guru. Para praktisi tersebut membutuhkan data yang bersifat detail pada suatu kasus yang diteliti untuk digunakan dalam perbaikan kinerja secara intensif. (Indrawan dan Poppy, 2017: 67).

Penelitian ini memiliki 3 (tiga) tujuan yaitu (1) mendeskripsikan faktor pengemudi Grab menggunakan aplikasi fake gps dan yang tidak menggunakan aplikasi fake gps, (2) mendeskripsikan pola interaksi antara pengemudi yang menggunakan aplikasi fake gps dan yang tidak menggunakan aplikasi fake gps, (3) mendeskripsikan bahwa kelompok dalam masyarakat bisa dijadikan sumber belajar sosiologi kelas $\mathrm{X}$ di SMA.

\section{METODE}

Penelitian tentang pola interaksi sosial pengemudi transportasi online Grab di Kota Singaraja pada saat pengemudi Grab bekerja di lapangan menggunakan pendekatan deskriptif kualitatif deskriptif. Teknik pengumpalan data purposive sampling, adalah teknik untuk mendapatkan sample yang langsung dilakukan secara langsung. Dengan metode pengumpulan data observasi, wawancara in-dept interview dilakukan secara langsung dengan media sosial 
Whatssapp mengingat situasi dan kondisi masih dalam keadaan pandemi Covid-19, dan studi dokumentasi. Teknik analisis data yang digunakan pada penelitian ini yaitu pengumpulan data, reduksi data, penyajian data, dan penarikan kesimpulan Subyek dalam penelitian ini adalah manajemen Grab Singaraja, koordinator Grab Singaraja, Pengemudi Grab Singaraja, dan guru sosiologi SMA Negeri 1 Sukasada.

\section{HASIL DAN PEMBAHASAN}

1. Gambaran Umum

Kota Singaraja adalah termasuk bagian dari wilayah administrasi Kabupaten Buleleng. Ketika dari pola pemukiman Kota Singaraja ini sudah mengarah pada perkotaan dengan heteregonitas yang cukup tinggi. Batasbatas administrasi Kota Singaraja sebelah utara laut bali, sebelah selatan Desa Git-git, sebelah timur Desa Kerobokan, sebelah barat Desa Pemaron. Orientasi wilayah Kota Singaraja dapat dilihat secara geografis terletak di $8^{\circ} 3^{\prime} 40^{\prime \prime}-8^{\circ} 23^{\prime} 00^{\prime \prime}$ LS dan $114^{\circ}$ 25' 55" - $1155^{\circ} 27^{\prime} 28^{\prime \prime}$ BT. Luas seluruh wilayah adalah $27,89 \mathrm{~km}^{2}$, memiliki lahan sawah seluas $844,15 \mathrm{~km}^{2}$, memiliki luas tegal $464,46 \mathrm{~km}^{2}$, memiliki luas perkebunan $121 \mathrm{~km}^{2}$, memiliki luas pekarangan 1063,46 $\mathrm{km}^{2}$, kemudian memiliki luas lahan kuburan $6,61 \mathrm{~km}^{2}$, dan luas lain-lain yakni 216,09 $\mathrm{km}^{2}$. Kota Singaraja memiliki jumlah penduduk sebanyak 82.527 jiwa kemudian memiliki kepadatan penduduk $3.200 \mathrm{jiwa} / \mathrm{km}^{2}$ dan rata-rata pertumbuhan penduduk mencapai 1,01\%/th. Berdasarkan data kependudukan tersebut Kota Singaraja dapat digolongkan kepada kelas Kota kecil, yang dimana berdasarkan kriteria BPS mengenai kelas Kota, Kota Kecil adalah Kota yang memiliki jumlah sekitar 20.000 sampai 100.00 jiwa.

Perkembangan komunikasi menggunaan Handphone dan Internet di Kota Singaraja, berdasarkan pengguna handphone dan internet khususnya di Kota Singaraja sudah berkembang pesat, hal ini ditunjukan berdasarkan data statistik kesejahteraan rakyat Kabupaten
Buleleng untuk pengguna handphone sebanyak 58.000 jiwa, kemudian diklasifikasikan kembali yang menggunakan handphone dan internet sejumlah 30.000 jiwa. Dengan didukungnya penggunaan handphone dan fasilitas internet yang memadai di Kota Singaraja berdasar data tersebut segala macam aplikasi bisnis khususnya aplikasi Grab bisa berkembang dan beroperasi di wilayah Singaraja, kemudian pengguna fasilitas tersebut bisa memanfaatkan untuk mengakses aplikasi Grab untuk konsumen hingga aplikasi untuk pengemudi transportasi online Grab. Faktor berkembangnya Grab di Kota Singaraja Terkait perkembangan teknologi komunikasi di Kota Singaraja dapat dilihat pada bagian diatas yang mengemukakan pengguna handphone sebanyak 58.000 jiwa serta pengguna handphone dengan fasilitas internet sudah mencapai 30.000 jiwa. Sehingga layanan aplikasi Grab dengan mudah berkembang di wilayah Singaraja karena didukung oleh fasilitas dan pengguna yang memadai, mengingat aplikasi Grab ini hanya bisa diakses melalui handphone yang ada jaringan internetnya. Terdapat faktor lain-lain berkembangnya Grab di Kota Singaraja yakni aplikasi Grab ini manfaat bagi pengemudi transportasi online dan konsumen transportasi online yang kedua belah pihak tersebut sama-sama diuntungkan. Khusunya untuk konsumen aplikasi Grab di Kota Singaraja bisa mudah untuk mencari ojek tanpa harus keluar rumah, yang dimana aplikasi memberi fasilitas yang bisa memudahkan konsumen seperti ada layanan aplikasi ojek, layanan aplikasi untuk membelikan makanan, serta ada layanan aplikasi pengantar barang.

Sejarah berdirinya transportasi online Grab di Kota Singaraja, berdasarkan wawancara dengan Bapak Gede Ady Pratama selaku manajemen Grab Singaraja mengemukakan bahwa Grab sudah mulai melakukan promosi sebelum tahun 2017, akan tetapi belum menunjukan perkembangan yang signifikan, baru pada tahun 2017 Grab di singaraja mulai aktif dan pada tahun 2017 
tersebut Grab berdiri di Kota Singaraja, pada tahun tersebut Grab terus gencar melakukan promosi sampai akhirnya memiliki Mitra begitu banyak, pada saat itu Grab belum memiliki kantor sehingga pihak Grab mencari partner kerja hingga sampai akhirnya Grab mendapatkan partner yang menyediakan tempat/basecamp pendaftaran, informasi, dan lain-lain yakni di Warung Nangkring jalan Ahmad Yani. Seiring gencarnya promosi Grab di Kota Singaraja pengemudi transportasi online Grab di Kota Singaraja dari tahun 2018-2019 jumlah keseluruhan Grab yang terdaftar adalah sekitar 2000 pengemudi dengan rincian $80 \%$ pengemudi motor dan $20 \%$ pengemudi mobil, kemudian berdasarkan evaluasi dari pihak manajemen Grab Singaraja pengemudi yang aktif bekerja adalah sekitar $50 \%$ atau hanya setengahnya. Data secara detail tidak boleh dipublikasikan oleh pihak manajemen Grab sehingga yang hanya bisa dipaparkan adalah jumlah gambaran umum yang sudah dipaparkan. Dengan bertambah banyaknya pengemudi transportasi online Grab di Kota Singaraja dari pihak manajemen memutuskan untuk membuat komunitas-komunitas untuk mempermudah dalam menghandle dan menyampaikan informasi penting dari pusat, dalam komunitas tersebut terdapat koordinator lapangan yang bertugas untuk menjadi penyambung dari pihak manajemen ke pihak pengemudi transportasi online ketika ada informasi penting. Dalam sistem manajemen Grab terdapat beberapa perangkat penting seperti Leader Grab Buleleng, staff manajemen Grab Singaraja, Koordinator lapangan Grab Singaraja, dan anggota/pengemudi transportasi online Grab di Kota Singaraja.

Dengan jumlah pengemudi jumlah pengemudi yang semakin banyak dan persaingan pun menjadi semakin ketat untuk bisa mendapatkan orderan sehingga pengemudi transportasi online melakukan melakukan berbagai cara untuk mendapatkan orderan salah satunya adalah menggunakan aplikasi fake gps.

\section{Faktor Munculnya Penggunaan Fake gps di Kota Singaraja.}

Berdasarkan wawancara yang dilakukan dengan pengemudi transportasi online yang tidak menggunakan fake gps yakni Bapak Putu Adi Sucita (41 tahun) memaparkan bahwa dalam mendapatkan pelanggan transportasi online itu sulit, secara tidak langsung untuk mendapatkan bonus dari Grab juga sulit. Ketika pengemudi merasa sulit dalam mendapatkan pelanggan untuk memperoleh penghasilan yang cukup. Untuk memperoleh penghasilan yang cukup pengemudi transportasi online menggunakan cara untuk mempermudah dalam mendapatkan pelanggan. Untuk memastikan kembali mengapa pengemudi transportasi online ada yang menggunakan aplikasi fake gps peneliti menanyakan langsung kepada pihak pemakai yang tidak bersedia disebutkan namanya kita sebut saja Garok (25 tahun) mendapatkan keterangan bahwa pengemudi transportasi online menggunakan fake gps bertujuan untuk mempermudah dari cara kerja sebagai pengemudi, dengan menambahkan aplikasi fake gps di aplikasi Grab pengemudi, sehingga pengemudi yang menggukan fake gps dapat memindahkan titik kordinat suatu lokasi yang dianggap ramai order tanpa perlu keliling seperti pengemudi yang tidak menggunakan fake gps. Pengguna fake gps diberi kemudahan dalam mendapatkan pelanggan dibanding pengemudi yang tidak menggunakan, pengemudi transportasi online bisa bekerja dari rumah masing-masing dengan menggunakan aplikasi tambahan ini serta mendapatkan order dengan maksimal, dengan demikian pengemudi transportasi online Grab yang menggunakan fake gps bisa mencapai target order untuk mendapatkan bonus dari Grab.

Dari hasil wawancara yang dilaksanakan mendapatkan hasil bahwa penggunaan fake gps dikalangan pengemudi transportasi online adalah salah satu wujud untuk memenuhi kebutuhan dari pengemudi online tersebut untuk memenuhi target dan untuk 
medapatkan penghasilan yang maksimal. Menurut McClelland (dalam Andjarwati, 2015) Menyampaikan teori motivasi ini erat sekali dengan hubungan kebutuhan. Teori tersebut mengemukakan bahwa ketika seseorang memiliki kebutuhan yang kuat, ini berdampak dalam memotivasi seseorang untuk menggunakan perilaku yang mengarah kepada pemenuhan kebutuhan untuk kepuasan. Kemudian Mclelland mengemukan terdapat 3 (tiga) konsep kebutuhan yakni motivasi pencapaian, motivasi berkuasa, dan motivasi untuk bersahabat. Berdasarkan ketiga konsep tersebut pada kalangan pengemudi transportasi online ini penggunaan fake gps ini menunjukan untuk memenuhi pencapaian untuk memenuhi syarat atau target dalam memperoleh bonus/insentif dari Grab untuk mendapatkan pendapatan yang maksimal.

\section{Pola Interaksi Pengemudi Grab yang menggunakan aplikasi Fake gps dan yang Tidak menggunakan aplikasi Fake gps di Kota Singaraja}

Menurut Bonner (dalam Sofiyana, 2013) mengemukakan bahwa interaksi sosial merupakan hubungan antara dua orang lebih atau individu, dimana kelakuan individu mempengaruhi, mengubah, atau mempengaruhi individu lain atau sebaliknya. Interaksi sosial adalah sebuah kunci dalam kehidupan sosial karena tanpa interaksi sosial tidak akan mungkin ada kehidupan bersama. Selanjutnya bertemunya orang-orang dengan badaniyah saja tidak akan menghasilkan pergaulan hidup di suatu kelompok sosial tertentu (Hardani, 2019). Ketika dikaitkan dengan fenomena pengemudi transportasi online Grab di Singaraja interaksi yang terjadi berdasarkan proses antara pengemudi transportasi online yang menggunakan aplikasi tambahan fake gps dan yang tidak menggunakan fake gps ini terjadi proses interaksi yang asosiatif dan disosiatif.

Pola interaksi sosial yang asosiatif pada kalangan pengemudi transportasi online di Kota Singaraja sebagai berikut: (a). Kerja sama, H. Husnadi (dalam Sofiyana, 2013) menyebutkan bahwa kerja sama adalah sebagai dua orang atau lebih untuk melakukan kegiatan secara bersama dan dilakukan secara terpadu kemudian diarahkan kepada target dan arah tertentu. Berdasarkan wawancara dengan Bapak I Putu Adi Sucitra (41 tahun) mengemukakan bahwa ketika ada salah satu pengemudi transportasi online yang mengalami musibah seperti kecelakaan dan lain-lain maka seluruh pengemudi akan bekerjasama dengan menyumbangkan donasi kepada pihak yang mengalami musibah agar beban yang diemban menjadi lebih ringan, dengan demikian kerja sama masih tertanam dalam pengemudi transportasi online Grab Singaraja ini. (b) Akomodasi, adalah suatu proses penyesuaian individu dengan individu, individu dengan kelompok, kelompok dengan kelompok guna mencegah, mengurangi, dan mengatasi ketegangan dan kekacauan dari kelompok sosial yang ada (Muslim, 2013). Salah satu pengemudi transportasi online Grab Singaraja yaitu I Putu Eka Hariawan (21 tahun) memaparkan bahwa Grab untuk menangani permasalahan yang ada, kemudian pihak menajemen mengumpulkan semua pengemudi transportasi online Grab Singaraja untuk membahas permasalahan tersebut, serta pihak Manajemen Grab menjadi mediator untuk menyelesaikan permasalahan tersebut. Berdasarkan tersebut dari pihak manajemen sebagai mediator dalam menyelesaikan permasalahan yang ada dengan demikian terdapat unsur akomodasi dalam tatanan pengemudi transportasi online Grab di Kota Singaraja. (c) Asimilasi, adalah sebuah proses sosial dalam taraf lanjut yang ditandai dengan adanya usaha-usaha mengurangi perbedaan yang terdapat diantara suatu individu atau kelompok sosial guna mementingkan kepentingan bersama dari segi prosesnya. Asimilasi merupakan proses perubahan pola sosial kebudayaan untuk menyesuaikan diri dengan mayoritas yang ada (Romli, 2015). Berdasarkan pemaparan dari salah satu pengemudi transportasi online yang 
menggunakan fake gps yakni Garok (25 tahun memaparkan sudah mengetahui jika menggunakan fake gps ini adalah suatu pelanggaran yang berat dan mengakibatkan putus hubungan kemitraan, ketika sudah mengetahui resikonya seperti itu masih banyak pengemudi yang menggunakan fake gps tersebut karena melihat penggunaan tersebut lumrah dan wajar yang jelas-jelas penggunaan aplikasi tambahan tersebut pelanggaran yang berat. Dari pemaparan tersebut sebenarnya pengemudi transportasi online sudah mengetahui larangan tersebut, akan tetapi tetap menggunakannya dengan demikian dalam pengemudi transportasi online masih terdapat unsur asimilasi.

Pola interaksi sosial yang disosiatif pada kalangan pengemudi transportasi online di Kota Singaraja sebagai berikut: (a) Persaingan, Menurut soekanto (dalam Hadari, 2019) Persaingan adalah proses sosial ketika individu atau kelompok manusia bersaing serta berlomba-lomba dalam mencari keuntungan melalui bidang-bidang tertentu untuk mencapai kemenangan atau keuntungan. Menurut pemaparan dari salah satu narasumber yakni Bapak I Putu Adi Sucitra (41 tahun) mengemukakan bahwa Persaingan yang terdapat di seluruh pengemudi transportasi online ada persaingan, dalam persaingan tersebut dengan cara mencari wilayah yan ramai dengan pemesan dan mendapatkan pelanggan yang banyak, akan tetapi persaingan tersebut semua bersifat sehat karena banyak tidaknya mendapat pelanggan itu berdasarkan dari server Grab yang ada. Dengan demikian persaingan yang terjadi adalah pengemudi untuk menemukan tempat strategis untuk mendapatkan orderan yang banyak. (b) Kontravensi, Menurut Soekanto (dalam Astiawan, dkk, 2018) kontravensi adalah salah satu bentuk proses sosial yang menunjukan adanya ketidaksenangan atau ketidakpuasan terhadap pihak lain baik secara tersembunyi atau terangterangan. Berdasarkan pemaparan Bapak I Putu Adi Sucitra (41 tahun) jelas masih terdapat pertentangan dari penggunaan fake gps tersebut dengan menolak keras penggunaannya, untuk menyelaraskan peneliti mendapat pemaparan dari pengemudi transportasi online yang menggunakan fake gps yakni Ronald (21 Tahun) yang mengemukakan bahwa sering terjadi pertentangan dari pengemudi yang tidak menggunakan aplikasi ini. Dengan berdasarkan pemaparan dari dua narasumber ini dapat dipastikan dalam pengemudi transportasi online masih terdapat unsur kontravensi. (c) Pertentangan atu konflik, Menurut Maryati (dalam Sofiyana, 2013) pertentangan atau konlfik individu maupun kelompok menyadari bahwa ada perbedaan-perbedaan dari segi ciri badaniyah, emosi, unsur-unsur kebudayaan, pola perilaku, dan lain sebagainnya. Berdasarkan pemaparan narasumber selaku koordinator lapangan Grab Bapak Putu Gede Ari Wibawa (34 tahun) memaparkan bahwa sudah terjadi konflik fisik akibat pertentangan dari penggunaan aplikasi fake gps di Singaraja.

\section{Aspek-Aspek Yang Dapat Dijadikan Sebagai Sumber Belajar Sosiologi Kelas X Di SMA}

Sehubungan dengan pembahasan yang ada, yaitu terkait tentang pola interaksi sosial pengemudi transportasi online Grab di Kota Singaraja, oleh karena itu pola interaksi pengemudi transportasi online Grab di Kota Singaraja menjadi analisis sumber belajar di Sekolah Menengah Atas 1 Sukasada, mengingat secara geografis SMAN 1 Sukasada dekat dengan Kota Singaraja, Bali, sehingga bisa memberi materi interaksi sosial dengan mengambil contoh pola interaksi pengemudi transportasi online Grab di Kota Singaraja. Berdasarkan wawancara dengan lbu Dra. Eny Fendriati (52 tahun) mengemukakan bahwa pola interaksi sosial kalangan pengemdudi transportasi online dapat dijadikan sebagai sumber belajar sosiologi kela $X$ di SMA ketika meilhat unsur-unsur sosiologis seperti interasksi sosial. Dalam temuan dari materi pembelajaran yang dimuat dalam 
buku yang berjudul Sosiologi Peminatan IImu-ilmu Sosial untuk SMAN/MA kelas $\mathrm{X}$ diterbitkan oleh CV Mediatama terdapat poin tentang Hubungan/interaksi Sosial di Masayarakat. Selanjuntnya poin-poin inti yang dapat dimuat dalam pembelajaran adalah tentang konsep interaksi sosial dan bentuk interaksi sosial pada kalangan pengemudi transportasi online Grab di Kota Singaraja. Untuk merelevansikan tulisan ini peneliti menganalisis kurikukulum K-13 mata pelajaran Sosiologi dengan memperhatikan kompetensi inti dan kompetensi dasar, menganalis silabus mata pelajaran sosiologi kelas $X$ di SMA, yang terakhir membuat alteratif rancangan pelaksanaan pembelajaran (RPP).

\section{Implikasi Penelitian}

Munculnya penggunaan fake gps adalah beraral dari faktor kebutuhan pengemudi transpoortasi online dan menimbulkan penyimpangan sosial dari penggunaan fake gps tersebut dan berimplikasi kepada pengemudi trasnportasi online itu sendiri.

Pola interaksi dari pengemudi transportasi online berimplikasi pada terbentuknya pola atau bentuk interaksi sosial pada kalangan pengemudi trasnportasi online Grab di Kota Singaraja.

Aspek-aspek dari interaksi sosial diantara pengemudi transportasi online Grab di Kota Singaraja yang dapat dijadikan sumber belajar berimplikasi kepada pendidik mata pelajaran sosiologi dalam materi realitas hubungan sosial di masyarakat dengan memberikan materi tentang pola interaksi sosial pengemudi transportasi online yang ada pada lingkungan sekitar.

\section{SIMPULAN DAN SARAN}

Berdasarkan hasil temuan dan analisis penelitian ini maka peneliti dapat menyimpulkan sebagai berikut,

Faktor munculnya penggunaan
fake gps dikalangan pengemudi
transportasi online Grab berdasarkan ketiga konsep kebutuhan tersebut pada kalangan pengemudi transportasi online ini penggunaan fake gps ini menunjukan untuk memenuhi kebutuhan akan pencapaian untuk memenuhi syarat atau target dalam memperoleh bonus/insentif dari Grab untuk mendapatkan pendapatan yang maksimal.

Pola interasksi sosial pengemudi Grab yang menggunakan aplikasi fake gps dan yang tidak menggunakan aplikasi fake gps yang dari segi prosesnya terdapat interaksi asosiatif dan disosiatif. Dari asosiatif terdapat unsur kerja sama, akomodasi, dan asimilasi. Jika dari segi disosiatif terdapat unsur persaingan, kontravensi, dan pertentangan/konflik pada kalangan pengemudi transportasi online Grab di Kota Singaraja.

Aspek-aspek yang dapat dijadikan sumber belajar sosiologi di SMA), adalah tentang interaksi sosial yang ada di kalangan pengemudi transportasi online Grab Singaraja dari bentuk interaksi sosial asosiatif dan interaksi sosial disosiatif.

Implikasi penelitian ini ditandai dengan munculnya penggunaan fake gps adalah beraral dari faktor kebutuhan pengemudi transportasi online dan menimbulkan penyimpangan sosial dari penggunaan fake gps tersebut dan berimplikasi kepada pengemudi trasnportasi online itu sendiri.

Pola interaksi dari pengemudi transportasi online berimplikasi pada terbentuknya pola atau bentuk interaksi sosial pada kalangan pengemudi trasnportasi online Grab di Kota Singaraja.

Aspek-aspek dari interaksi sosial diantara pengemudi transportasi online Grab di Kota Singaraja yang dapat dijadikan sumber belajar yang berimplikasi kepada pendidik mata pelajaran sosiologi dalam materi realitas hubungan sosial di masyarakat dengan memberikan materi tentang pola interaksi sosial pengemudi transportasi online yang ada pada lingkungan sekitar.

Terdapat saran terkait tulisan ini dari peneliti sebagai berikut, Untuk pihak manajemen Grab diharapkan untuk memperbaiki sistem aplikasi di Grab, agar supaya tidak ada penggunaan aplikasi fake gps yang menyebabkan ketidak rukunan antara pengemudi transportasi online Grab yang ada di seluruh 
indonesia, khususnya di Kota Singaraja. Terakhir Untuk pendidik mata pelajaran sosiologi di SMAN 1 Sukasada diharapkan untuk memperluas materi interaksi sosial dengan contoh-contoh yang ada di lingkungan sekitar yang kiranya belum diketahui oleh peserta didik, agar supaya peserta didik menjadi lebih paham dan luas wawasannya.

\section{DAFTAR PUSTAKA}

Buku:

Indrawan dan Poppy. 2017. Metodologi Penelitian Kuantitatif, Kualitatif, dan Campuran untuk Manajemen, pembangunan, dan Pendidikan. Bandung: PT Refika Aditama

Jurnal:

Andjarwati, T. 2015. Motivasi dari Sudut Pandang Teori Hirarki Kebutuhan Maslow, Teori Dua Faktor Herberg, Teori X Y Mc Gregor, dan Teori Motivasi Mc Clelland. (Diterbitkan). Dosen Fakultas Ekonomi, Universitas 17 Agustus 1945 Surabaya.

Astiawan I, dkk. 2018. Pola Interaksi Sosial Anggota Subak Hindu dan NonHindu di Subak Pemaket Awen Selatan Desa

Pengambengan, Kecamatan

Negara, Kabupaten Jembrana. Jurnal (Diterbitkan) Fakultas Pertanian, Universitas Udayana.

Muslim, A. 2013. Interaksi Sosial dalam Masyarakat Multietnis. Jurnal (Diterbitkan). Fakultas Ushuluddin dan Filsafat, UIN Alauddin Makasar

Permatasary, N. 2019. Interaksi Sosial Penari Bujangganong pada Sale Creative Community di Desa Sale Kabupaten Rembang. Jurnal (Diterbitkan). Jurusan Sendratasik, Universitas Negeri Semarang.

Romli, K. 2015. Akulturasi dan Asimilasi dalam Konteks Interaksi Antar Etnik. Jurnal (Diterbitkan). Dosen
Fakultas Dakwah, IAIN Raden Intan Lampung.

Tola, F. 2016. Begal Motor Sebagai Perilaku Menyimpang Muslim Mappa. Jurnal (Diterbitkan). Universitas Muhammadiyah Makasar.

Artikel:

Ellpas. 2017. Apa itu Grab, ini penjelasan mudahnya. Diakses dari: https://www.elppas.com/2017/11/a pa-itu-grab-ini-penjelasan mudahnya.html (01 Desember 2019)

Grab. 2019. Kode Etik Grab. Diakses dari : https://www.grab.com/id/kodeetik/ (02 Desember 2019)

Guru Pendidikan. 2020. Penyimpangan Sosial: Pengertian, Contoh, Bentuk, Teori, Ciri, dan Solusi. Diakses dari: https://www.gurupendidikan.co.id/p enyimpangan-sosial/ (15 Juni 2020)

Hadari. 2019. Interaksi Sosial dalam Bentuk Kerja Sama dan Persaingan Santriawan Etnik Madura dan Melayu Darul Khairat. Progam Studi Pendidikan Sosiologi, FKIP Untan Pontianak.

Wahyusetyawati. $2017 . \quad$ Dilema Pengaturan Transportasi Online. Artikel (Diterbitkan). Media Pembelajaran Hukum Nasional

Statiskian. 2017. Teknik sampling dalam penelitian. Diakses dari https://www.statistikian.com/2017/0 6/teknik-sampling-dalampenelitian.html. (28 juli 2020)

Sumber Resmi:

Statistik Kesejahteraan Rakyat Kabupaten Buleleng. 2018: Buleleng: Badan Pusat Statistik Kabupaten Buleleng

Tugas Akhir:

Formaninsi, R. 2014. Stigma Masyarakat Terhadap Keluarga Pelaku Pembunuhan ( Studi Kasus Pada Keluarga Pelaku Pembunuhan di Kecamatan Padang Guci Hulu Kabupatenn Kaur Provinsi 
Bengkulu ). Skripsi. Universitas Bengkulu tidak diterbitkan.

Santoso, Y. 2018. Penggunaan Aplikasi Fake gps pada Pengemudi PT. Oke Jack Indonesia. Skripsi. Universitas Islam Sunan Ampel Surabaya tidak diterbitkan

Sofiyana, R. 2013. Pola Interaksi Masyarakat dengan Waria di Pondok Pesantren Khusus AlFatah Senin Kamis. Skripsi. Fakultas Pendidikan, Universitas Negeri Semarang tidak diterbitkan. 